\title{
Assessing neurophysiological changes associated with combined transcranial direct current stimulation and cognitive-emotional training for treatment- resistant depression
}

Citation for published version (APA):

Nikolin, S., Martin, D., Loo, C. K., lacoviello, B. M., \& Boonstra, T. W. (2020). Assessing neurophysiological changes associated with combined transcranial direct current stimulation and cognitive-emotional training for treatment-resistant depression. European Journal of Neuroscience, 51(10), 2119-2133. https://doi.org/10.1111/ejn.14656

Document status and date:

Published: 01/05/2020

DOI:

10.1111/ejn.14656

Document Version:

Publisher's PDF, also known as Version of record

Document license:

Taverne

Please check the document version of this publication:

- A submitted manuscript is the version of the article upon submission and before peer-review. There can be important differences between the submitted version and the official published version of record. People interested in the research are advised to contact the author for the final version of the publication, or visit the DOI to the publisher's website.

- The final author version and the galley proof are versions of the publication after peer review.

- The final published version features the final layout of the paper including the volume, issue and page numbers.

Link to publication

\footnotetext{
General rights rights.

- You may freely distribute the URL identifying the publication in the public portal. please follow below link for the End User Agreement:

www.umlib.nl/taverne-license

Take down policy

If you believe that this document breaches copyright please contact us at:

repository@maastrichtuniversity.nl

providing details and we will investigate your claim.
}

Copyright and moral rights for the publications made accessible in the public portal are retained by the authors and/or other copyright owners and it is a condition of accessing publications that users recognise and abide by the legal requirements associated with these

- Users may download and print one copy of any publication from the public portal for the purpose of private study or research.

- You may not further distribute the material or use it for any profit-making activity or commercial gain

If the publication is distributed under the terms of Article 25fa of the Dutch Copyright Act, indicated by the "Taverne" license above, 


\title{
Assessing neurophysiological changes associated with combined transcranial direct current stimulation and cognitive-emotional training for treatment-resistant depression
}

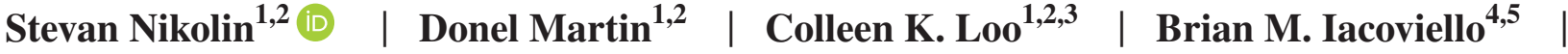 \\ Tjeerd W. Boonstra ${ }^{1,6}$ (D)
}

${ }^{1}$ School of Psychiatry, University of New South Wales, Sydney, NSW, Australia

${ }^{2}$ Black Dog Institute, Sydney, NSW,

Australia

${ }^{3}$ St. George Hospital, Sydney, NSW, Australia

${ }^{4}$ Click Therapeutics, Inc., New York, NY, USA

${ }^{5}$ Department of Psychiatry, Icahn School of Medicine at Mount Sinai, New York, NY, USA

${ }^{6}$ Faculty of Psychology and Neuroscience, Maastricht University, Maastricht, The Netherlands

\section{Correspondence}

Stevan Nikolin, School of Psychiatry, University of New South Wales, Sydney, NSW, Australia.

Email: stevan.nikolin@unsw.edu.au

Funding information

Brain and Behavior Research Foundation, Grant/Award Number: 24015 and 26060

\begin{abstract}
Transcranial direct current stimulation (tDCS), a form of non-invasive brain stimulation, is a promising treatment for depression. Recent research suggests that tDCS efficacy can be augmented using concurrent cognitive-emotional training (CET). However, the neurophysiological changes associated with this combined intervention remain to be elucidated. We therefore examined the effects of tDCS combined with CET using electroencephalography (EEG). A total of 20 participants with treatment-resistant depression took part in this open-label study and received 18 sessions over 6 weeks of tDCS and concurrent CET. Resting-state and task-related EEG during a 3-back working memory task were acquired at baseline and immediately following the treatment course. Results showed an improvement in mood and working memory accuracy, but not response time, following the intervention. We did not find significant effects of the intervention on resting-state power spectral density (frontal theta and alpha asymmetry), time-frequency power (alpha event-related desynchronisation and theta event-related synchronisation) or event-related potentials (P2 and P3 components). We therefore identified little evidence of neurophysiological changes associated with treatment using tDCS and concurrent CET, despite significant improvements in mood and near-transfer effects of cognitive training to working memory accuracy. Further research incorporating a sham-controlled group may be necessary to identify the neurophysiological effects of the intervention.
\end{abstract}

\section{K E Y W O R D S}

alpha asymmetry, EEG, event-related potential, tDCS, working memory

\footnotetext{
Abbreviations: CET, cognitive-emotional training; DLPFC, dorsolateral prefrontal cortex; EEG, electroencephalography; EFMT, Emotional Faces Memory Task; ERD, event-related desynchronisation; ERP, event-related potential; ERS, event-related synchronisation; ICA, independent component analysis; MADRS, Montgomery-Asberg Depression Rating Scale; MDD, major depressive disorder; PSD, power spectral density; RT, response time; tDCS, transcranial direct current stimulation; TOST, two one-sided $t$ test.

Edited by John Foxe.

The peer review history for this article is available at https://publons.com/publon/10.1111/ejn.14656
} 


\section{1 | INTRODUCTION}

Major depressive disorder (MDD) is a debilitating mental illness with a lifetime prevalence of 12\%-20\% (Mrazek, Hornberger, Altar, \& Degtiar, 2014). Transcranial direct current stimulation (tDCS), a mild, non-invasive method of brain stimulation, has shown promising therapeutic potential for the treatment of depression (Brunoni et al., 2016, 2017, 2013; Loo et al., 2012). However, results from a recent large controlled trial suggested that such antidepressant effects of tDCS when given alone are modest (Brunoni et al., 2017), raising the need for research into improving tDCS clinical outcomes. Combining tDCS with concurrent cognitive training (e.g. cognitive-emotional training, designed to activate brain regions associated with cognitive control and emotion processing) appears to be a promising method to further boost treatment outcomes (Martin et al., 2018). The neural pathways by which this novel combined intervention improves mood remain unknown. An examination of the neurophysiological changes associated with this approach may shed light on its mechanisms of action and pave the way for further augmentation of the therapy.

tDCS for depression involves the delivery of an electrical current, typically between 1 and $2.5 \mathrm{~mA}$, using a positively charged electrode placed on the scalp over the left dorsolateral prefrontal cortex (DLPFC) and a negatively charged electrode on a contralateral frontal region (Loo et al., 2018). Though research suggests that tDCS is an effective treatment in MDD in general (Mutz et al., 2019), the results in treatment-resistant depression appear less promising (Blumberger, Tran, Fitzgerald, Hoy, \& Daskalakis, 2012; Palm et al., 2012). Indeed, a meta-analysis of individual patient data found treatment resistance to be associated with reduced tDCS efficacy (Brunoni et al., 2016).

To improve therapeutic efficacy in people with treatment-resistant depression, some trials have combined tDCS with cognitive training (Brunoni et al., 2014; Segrave, Arnold, Hoy, \& Fitzgerald, 2014). It has been suggested that tDCS interacts with ongoing neuronal activity to boost synaptic plasticity within activated regions (Kronberg, Bridi, Abel, Bikson, \& Parra, 2017; Kronberg, Rahman, Lafon, Bikson, \& Parra, 2019). The administration of behavioural tasks during tDCS may thus be used to pre-activate relevant cortical regions and augment the neuromodulatory potential of tDCS by improving the functional specificity of stimulation (Bikson \& Rahman, 2013). Cognitive-emotional training (CET) is a form of computerised cognitive training which was designed to activate cognition and emotion processing circuits implicated in MDD to treat depressive symptoms (Iacoviello \& Charney, 2015; Iacoviello et al., 2014). Specifically, it involves training using an emotional working memory paradigm that aims to simultaneously activate brain regions in the cognitive control (i.e. prefrontal
cortex/DLPFC)) and affective networks (i.e. amygdala) to improve emotion regulation. A recent open-label pilot study conducted by our group combined tDCS with concurrent CET and reported a $41 \%$ response rate in treatment-resistant participants (Martin et al., 2018). The neurophysiological changes associated with this intervention, however, remain to be elucidated. Determination of such changes may provide insight into the mechanisms underlying the antidepressant response and inter-individual predictors which can assist with the further development and targeting of treatment.

Electroencephalography (EEG) allows for non-invasive assessment of brain activity and has been used to gain further insights into the functional changes associated with antidepressant response (Iosifescu, 2011). Given the paucity of research on the cumulative effects of tDCS on EEG outcomes, we investigate several EEG measures that have shown relevance in the broader depression and working memory literature. EEG markers acquired at rest can provide valuable information regarding severity of depression symptomatology. Frontal alpha asymmetry, in which higher alpha power is observed in the left compared to the right prefrontal cortex (Debener et al., 2000; Gordon, Palmer, \& Cooper, 2010; Stewart, Bismark, Towers, Coan, \& Allen, 2010), has been inversely correlated with depression scores (Diego, Field, \& Hernandez-Reif, 2001). Although recent research has questioned the diagnostic value of frontal alpha asymmetry as a biomarker for depression (Van Der Vinne, Vollebregt, Putten, \& Arns, 2017), alpha asymmetry has been associated with response to antidepressant medications (i.e. selective serotonin reuptake inhibitors) in females and may therefore have some prognostic value (Arns et al., 2016). As the combined tDCS and CET intervention involves concurrent stimulation and activation of left prefrontal regions, it is possible this measure may additionally show changes following treatment. In addition to alpha band activity, resting-state frontal theta power may also provide a marker for depression (Bailey et al., 2018; Iosifescu, 2011). Several studies have reported elevated frontal theta as a positive predictive factor for antidepressant response (Pizzagalli, Hendrick, Horras, \& Davidson, 2002; Spronk, Arns, Barnett, Cooper, \& Gordon, 2011; Rentzsch, Adli, Wiethoff, Castro, \& Gallinat, 2014; Arns et al., 2015; Koo, Thome, Berger, Foley, \& Hoeppner, 2017), although another study suggested that mood changes are negatively correlated with frontal theta activity (Knott, Mahoney, Kennedy, \& Evans, 2000).

Task-related EEG measures, such as event-related potentials (ERPs) and time-frequency power, have also shown sensitivity to the neurophysiological effects of tDCS as compared to behavioural outcomes on a working memory task (Nikolin, Martin, Loo, \& Boonstra, 2018b). Two ERP components, P2 and P3, have been found to be particularly sensitive to the effects of tDCS during a task of working memory, with both increasing in amplitude following stimulation of the prefrontal 
cortex (Keeser et al., 2011). The P2 amplitude reflects sustained attention and initiates context updating during working memory tasks (Kemp et al., 2006; Luu et al., 2014; Vilà-Balló et al., 2018; Yuan et al., 2016), and its amplitude has been observed to be positively correlated to working memory performance (Han, Liu, Zhang, Jin, \& Luo, 2013). The P3 component appears to reflect higher-order executive processes within the frontoparietal cortical network (Brydges \& Barceló, 2018; Polich, 2007) and has also been positively correlated with working memory capacity and task performance (Dong, Reder, Yao, Liu, \& Chen, 2015; Gajewski \& Falkenstein, 2018; Gevins \& Smith, 2000; Nikolin, Martin, et al., 2018b). Event-related synchronisation (ERS) and desynchronisation (ERD) during working memory cognitive processes have been mainly found in the theta and alpha band (Gomarus, Althaus, Wijers, \& Minderaa, 2006; Missonnier et al., 2006; Wianda \& Ross, 2019; Zhao, Li, \& Yao, 2017). In healthy individuals, anodal tDCS of the prefrontal cortex has been shown to improve working memory performance and increase event-related alpha and theta power (Zaehle, Sandmann, Thorne, Jäncke, \& Herrmann, 2011). Frontal theta ERS during working memory has been linked to allocation of attention to task-relevant stimuli (Missonnier et al., 2006). Both alpha ERD and theta ERS become more pronounced with increasing cognitive load (Klimesch, Doppelmayr, \& Hanslmayr, 2006; Klimesch et al., 2004; Krause et al., 2000; Stipacek, Grabner, Neuper, Fink, \& Neubauer, 2003), and frontal theta activity has been found to be reduced following active compared to sham tDCS during memory retrieval in depressed participants (Powell, Boonstra, Martin, Loo, \& Breakspear, 2014).

The clinical and cognitive outcomes of tDCS combined with concurrent CET for participants with treatment-resistant depression are reported in greater detail in a previous report from our group (Martin et al., 2018). Here, we sought to understand possible mechanisms underlying treatment effects of this novel intervention by examining neurophysiological changes using EEG. We hypothesised that tDCS combined with CET would restore cognitive control network functioning, observable as an improvement in working memory performance and a reduction in frontal alpha asymmetry and frontal theta recorded during resting-state EEG. Additionally, we hypothesised that the intervention would increase the amplitude of event-related EEG components $\mathrm{P} 2$ and P3. Finally, we anticipated a reduction in alpha ERD and theta ERS during the working memory task, indicative of improved cognitive processing efficiency.

\section{2 | MATERIALS AND METHODS}

\section{1 | Participants}

We recruited twenty participants with treatment-resistant depression, of which 10 were included in the sample analysed to investigate the clinical and cognitive efficacy of tDCS combined with CET (Martin et al., 2018). All participants were screened by a study psychiatrist and met DSM-IV criteria for a major depressive episode (APA (American Psychiatric Association), 1994). Additional inclusion criteria included: a score on the Montgomery-Asberg Depression Rating Scale (MADRS; Montgomery \& Asberg, 1979) $\geq 20$, treatment resistance as defined by failure to respond to at least two adequate courses of antidepressant medications and aged between 18 and 65 years old. Participants were excluded from the study if they had a neurological illness, were diagnosed with a psychotic disorder, had alcohol or illicit substance abuse, failed to respond to a course of electroconvulsive therapy in the current episode, had a high suicide risk or regularly used benzodiazepines. Participants were not permitted to change medications or their dosages in the four weeks preceding the study and for the duration of the combined tDCS and CET intervention. Written informed consent was provided by all participants, and the study was approved by the UNSW Human Research Ethics Committee.

\section{2 | Procedure}

Participants received a course of 18 sessions of tDCS combined with CET, delivered three times per week for six weeks, as described in Martin et al. (2018). Neurophysiological outcomes were assessed pre-treatment (BASELINE) and at the completion of 18 sessions of the intervention (POST) in a within-subjects open-label study design. EEG was recorded during $5 \mathrm{~min}$ of eyes-closed resting-state activity, followed by $5 \mathrm{~min}$ of eyes-open resting-state activity, and finally $7 \mathrm{~min}$ of task-related activity during a visual 3-back working memory task (Figure 1a). During the eyes-closed condition, participants were asked to close their eyes until the experimenter informed them that the EEG recording was complete. For the eyes-open condition, participants were asked to focus their gaze on a fixation cross displayed on a computer screen.

\section{3 | Transcranial direct current stimulation}

An Eldith DC-Stimulator (neuroConn GmbH, Germany) was used to deliver a $2 \mathrm{~mA}$ current for $40 \mathrm{~min}$ each session. This duration was chosen to ensure that participants were stimulated for the entirety of the CET intervention, and has been demonstrated to be safe and tolerable in previous studies (Bolognini et al., 2011; Gluck et al., 2015; Hamner, Villamar, Fregni, \& Taylor, 2015; Di Lazzaro et al., 2014). Anodal tDCS was applied using a $5 \times 7 \mathrm{~cm}$ $\left(35 \mathrm{~cm}^{2}\right)$ rubber electrode placed on the scalp directly over the left DLPFC (F3 using the 10-20 EEG system). An extracephalic $10 \times 10 \mathrm{~cm}\left(100 \mathrm{~cm}^{2}\right)$ return cathode was placed 
(a)

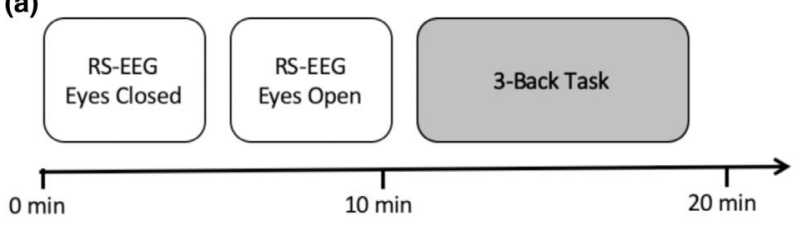

(b)

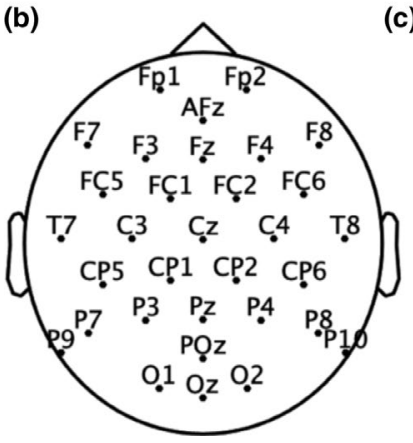

(c)

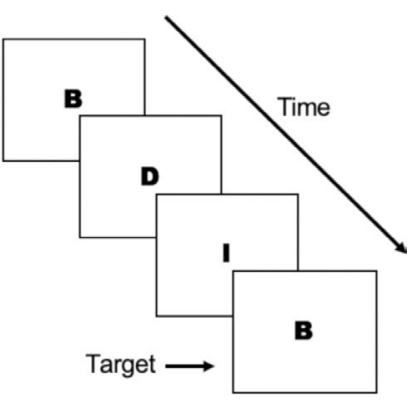

F I G URE 1 Experiment Details. (a) Illustration of the EEG protocol and timeline. Participants completed EEG testing at baseline, and following 18 sessions of tDCS combined with CET; (b) the EEG layout for 32 water-based electrode recording channels; (c) for the 3-back task, participants were asked to respond when the letter currently on the screen matched the letter presented three trials previously. RS-EEG, resting-state EEG

on the participant's right shoulder. An open-label pilot investigation found this montage resulted in more rapid mood improvement relative to a bifrontal (F3-F8) electrode placement (Martin et al., 2011), though its efficacy is yet to be confirmed in a randomised control trial. Computational modelling suggests that this montage increases the activation of limbic regions, such as the anterior cingulate cortex, as compared to bifrontal tDCS electrode placements commonly used for depression (Bai, Dokos, Ho, \& Loo, 2014). Sponges soaked in saline were used to improve conductivity between the electrodes and skin, and thereby minimise the risk of skin lesions (Loo et al., 2011).

\section{4 | Cognitive-emotional training}

The Emotional Faces Memory Task (EFMT) was used to provide CET and is described in greater detail in Iacoviello et al. (2014). In EFMT, participants observe a series of faces depicting various emotions (sadness, happiness, surprise and disgust) on a computer screen and respond (yes/ no) whether the emotion observed matched the emotion presented several (a set value, " $n$ ") trials previously, thus combining emotion processing and n-back working memory components. The task difficulty was adjusted according to participant performance by increasing or decreasing the number of emotional faces participants had to maintain in memory (n); task difficulty also progresses throughout an
EFMT session as the emotional intensity observed on the faces decreases.

\section{5 | Electroencephalography data acquisition}

Continuous EEG data were acquired using 32 water-based EEG recording channels and a TMSi Refa amplifier (TMS International, Oldenzaal, Netherlands; see Figure 1b). EEG processing and analysis were conducted using custom-developed MATLAB scripts (v.R2019a; MathWorks) and the FieldTrip toolbox (Oostenveld, Fries, Maris, \& Schoffelen, 2011). All scripts used for EEG processing and calculation of neurophysiological measures are available at the following link (https://github.com/snikolin/tDCSandCET).

EEG data were sampled at $1024 \mathrm{~Hz}$ and filtered using a bandpass filter $(0.5-70 \mathrm{~Hz})$ and a notch filter at $50 \mathrm{~Hz}$ to remove electrical line noise. Data were epoched in 2-s intervals and inspected using a semi-automated algorithm to remove epochs containing artefacts. Independent component analysis (ICA) was then used to remove eye blink and muscle artefacts. Following ICA, EEG data were re-referenced to the common average reference.

\section{6 | Behavioural measures}

Mood was assessed using the MADRS, a validated clinicianrated scale of depression symptom severity (Montgomery \& Asberg, 1979). Response and remission were defined as a reduction in MADRS $\geq 50 \%$ from baseline and a post-intervention MADRS total score $<10$, respectively.

The visual 3-back task, adapted from Mull and Seyal (2001), was administered using Inquisit 4 software (version 4, Millisecond Software) to assess working memory. Participants were asked to observe a sequence of letter stimuli presented on a computer screen in random order and respond (by pressing the space bar on a keyboard) when the target letter currently on the screen matched the letter presented three trials previously (see Figure 1c). The 3-back task is therefore similar to the Emotional Faces Memory Training task used for CET, but does not require processing of emotional content. The 3-back task consisted of 40 target letters interspersed with 180 non-targets, with a 2 -s interval between successive letters. Prior to the start of each experiment, participants practised the task for approximately 5 min to ensure they understood task instructions. The 3-back task was selected because it is considered challenging, requiring greater attentional and executive resources, and so reduces the likelihood of ceiling effects for participants that improved cognitively over the 6-week intervention. The working memory outcome measures were response time (RT) for correct responses and d-prime, a measure of discriminate sensitivity (Haatveit et al., 2010). 


\subsection{Neurophysiological measures}

\subsection{1 | Resting-state power spectral density}

Power spectra were calculated for resting-state EEG under eyes-open and eyes-closed conditions. Data from the first $15 \mathrm{~s}$ were discarded to ensure participants were completely at rest in the time window being analysed and power spectral densities (PSD) were estimated using $285 \mathrm{~s}$ of data. Log-normalised power spectral density values $\left(\mu \mathrm{V}^{2} / \mathrm{Hz}\right)$ were estimated for each EEG electrode over a range of $1-70 \mathrm{~Hz}$ using the fast Fourier transform with 2-s sliding Hamming windows with 50\% overlap, as initially described by Welch (1967).

Frontal alpha asymmetry was obtained under the eyesclosed resting-state EEG condition (Van Der Vinne et al., 2017). To calculate this index, power in the alpha frequency band $(8-13 \mathrm{~Hz})$ was obtained at EEG channels F3 and F4. We then divided the difference in alpha power between channels by the sum of alpha power between channels: (F4 - F3)/(F4 + F3).

Frontal theta was calculated as the average of power in the theta frequency band (4-8 Hz) at anterior EEG channels Fp1, Fp2, Afz, F3, Fz and F4 under the eyes-closed resting-state EEG condition.

\subsection{2 | Event-related potentials}

Event-related potentials (ERPs) were calculated by averaging across target and non-target trials from the 3-back task. Poststimulus activity was baseline-corrected using the mean amplitude from $500 \mathrm{~ms}$ to $0 \mathrm{~ms}$ prior to stimulus onset. Average amplitudes for ERP components P2 and P3 were measured from frontal EEG channel Fz. The time window for averaging was determined by computing the grand average ERP component across BASELINE and POST periods for all participants and isolating the mean latency for the $\mathrm{P} 2$ and $\mathrm{P} 3$ components. The average amplitude was then calculated for each participant in a time window $\pm 20 \mathrm{~ms}$ around the grand average latencies for $\mathrm{P} 2$ and $\mathrm{P} 3$ components from the previous step. The latency of the $\mathrm{P} 2$ component was identified as $145.5 \mathrm{~ms}$ post-stimulus (time window for averaging: $125.5-165.5 \mathrm{~ms}$ ), and the latency for the P3 component was $373.0 \mathrm{~ms}$ (time window for averaging: 353.0-393.0 ms) following stimulus onset.

\subsection{3 | Time-frequency analysis}

Similar to ERP measures, time-frequency power was calculated by averaging across target and non-target trials from the 3-back task. We used a Hanning taper with a fixed $500 \mathrm{~ms}$ time window. Power values were baseline-corrected using activity from $500 \mathrm{~ms}$ to $0 \mathrm{~ms}$ prior to stimulus onset and transformed into a decibel scale $(10 * \log 10$ of the signal).
Alpha event-related desynchronisation (ERD) was operationalised as band power $200-700 \mathrm{~ms}$ from stimulus onset in the alpha frequency band $(8-12 \mathrm{~Hz})$. Theta event-related synchronisation (ERS) was defined as band power 0-500 ms from stimulus onset in the theta frequency band $(4-8 \mathrm{~Hz})$.

\section{8 $\quad$ Statistical analysis}

Statistical analyses were performed using R statistical software version 3.5.1 (R Core Team, 2018) and the FieldTrip MATLAB toolbox (Oostenveld et al., 2011). Scripts used for statistical analysis are available at the following link (https:// github.com/snikolin/tDCSandCET). Two-tailed paired-samples $t$ tests were performed for mood, working memory and EEG neurophysiological outcomes to evaluate changes from BASELINE to POST. Normality of paired differences was tested using the Shapiro-Wilk test. A $p$-value of $<.05$ was considered non-normally distributed, in which case we additionally performed a non-parametric Wilcoxon signed-rank test. We applied a Bonferroni correction to the six neurophysiological outcomes to reduce the false-positive (Type 1) error associated with multiple comparisons. As such, the threshold for statistical significance for EEG measures was set at $p=.008$ (i.e. 0.05/6).

Repeated measures and Spearman correlations between behavioural and neurophysiological measures are also provided in Supplementary Materials (see Tables S1 and S2).

\subsubsection{Equivalence tests}

A within-subjects study design of $n=20$ allows for the detection of moderate-large effect sizes of Cohen's $d \geq 0.65$ using $\alpha=0.05$ and $80 \%$ statistical power. Therefore, lack of statistical significance on a paired-samples $t$ test may be indicative of no effect or of insufficient power to detect effects sizes smaller than this threshold. To statistically reject the possibility of non-trivial effect sizes, we performed two onesided $t$ test (TOST) equivalence procedures using Cohen's $d=0.3$ as the smallest effect size of interest. Thus, a significant equivalence test result would suggest an effect size of $d<0.3$. This procedure was performed using the $\mathrm{R}$ package, TOSTER and the TOSTpaired function (Lakens, 2017).

\subsection{2 | Non-parametric cluster-based permutation tests}

In additional to the previous analyses for single electrodes (or averages of a small number of electrodes), we also conducted exploratory non-parametric cluster-based permutation analyses on the entire EEG data set for measures extracted using power spectral density, event-related potential 
and time-frequency analyses. This method controls for multiple comparisons while assessing global changes from BASELINE to POST across all EEG channels, frequency ranges and post-stimulus time points for event-related measures (i.e. ERPs and ERS/ERD), changes that were not otherwise hypothesised a priori (Maris \& Oostenveld, 2007).

The Monte Carlo method was used, whereby trials were randomly permuted in 3,000 iterations and the resulting distributions were statistically compared using dependent samples $t$ tests. A two-tailed significance threshold of $\alpha<0.05$ was adopted as the cluster threshold and significance threshold for all analyses. Cluster-based permutation tests commonly require clusters of at least two neighbouring channels; however, due to the limited number of EEG channels in the current experiment, we opted for a less conservative threshold of at least one neighbouring channel.

For ERPs and ERS/ERD, the non-parametric cluster-based permutation tests were performed on a time interval of interest $0-1,000 \mathrm{~ms}$ from the onset of 3-back task letter stimuli. For neurophysiological outcomes with frequency information, including resting-state PSDs and ERS/ $\mathrm{ERD}$, permutation testing was conducted in the frequency band of $1-70 \mathrm{~Hz}$.

\section{3 | RESULTS}

A total of twenty participants with treatment-resistant depression completed 18 sessions of tDCS combined with CET. Table 1 shows baseline demographic and clinical information for the sample.

\section{1 | Behavioural outcomes}

A summary of statistical outcomes for behavioural measures is provided in Table 2. tDCS combined with CET was found to significantly reduce symptoms of depression $(p<.001)$. Eight participants met the response criterion (40\%), and three participants were remitters upon the completion of 18 sessions of treatment (15\%). Mood improvements persisted at the 1-month follow-up $\left(n=14, t_{13}=-3.56, p=.003\right.$, $d=0.94$ ), but were no longer significant at the 3 -month follow-up, in which only half of the original sample remained $\left(n=10, t_{9}=-2.17, p=.06, d=0.69\right)$. Participants significantly improved on working memory d-prime $(p=.03)$, but not response time ( $p=.45$; see Figure 2$)$.

\section{2 | Neurophysiological outcomes}

A summary of statistical outcomes for neurophysiological measures is provided in Table 2 . Frontal alpha asymmetry,
TA B LE 1 Baseline demographic and clinical information

\begin{tabular}{|ll|}
\hline Variable & Mean (SD) \\
\hline Sample $(n)$ & 20 \\
\hline Age (years) & $45.1(12.2)$ \\
\hline Years of education & $13.8(2.17)$ \\
\hline Age at onset (years) & $23.2(10.2)$ \\
\hline Gender, females $(n)$ & 12 \\
\hline Medications & \\
\hline Concurrent antidepressants & 15 \\
\hline SSRI or SSNRI & 6 \\
\hline TCA & 4 \\
\hline MAOI & 3 \\
\hline Antipsychotic & 5 \\
\hline Anticonvulsant & 5 \\
\hline Lithium & 3 \\
\hline Clinical characteristics & \\
\hline Number of antidepressant courses failed during & $2.15(1.81)$ \\
\hline the current episode & $4.65(2.11)$ \\
\hline Number of lifetime antidepressant courses failed & $44.5(68.7)$ \\
\hline Duration of current episode (months) & $54.2(71.0)$ \\
\hline Duration of previous episodes (months) & $6.85(2.41)$ \\
\hline Maudsley Treatment Resistance & $30.0(5.15)$ \\
\hline Baseline MADRS & \\
\hline
\end{tabular}

Note: SSRI, selective serotonin reuptake inhibitor; SSNRI, selective serotoninnorepinephrine reuptake inhibitor; TCA, tricyclic antidepressant; MAOI, monoamine oxidase inhibitor; Maudsley Treatment Resistance: Total score on the Maudsley Staging Method (Fekadu et al., 2009); MADRS, MontgomeryAsberg Depression Rating Scale (Montgomery \& Asberg, 1979).

frontal theta and theta ERS were not normally distributed; thus, additional Wilcoxon signed-rank tests were performed.

\subsection{1 | Resting-state power spectral density}

There were no significant effects for frontal alpha asymmetry ( $p=.59$; Wilcoxon signed-rank test, $p=.70$ ) or frontal theta $(p=.73$; Wilcoxon signed-rank test, $p=.96)$ change from BASELINE to POST time periods. Equivalence testing for both measures was not significant; thus, an effect size greater than $d=0.3$ cannot be statistically rejected. Exploratory cluster-based permutation testing did not reveal any significant spectral power changes for any frequency band for eyes-closed or eyes-open resting-state EEG conditions (see Figure 3).

\subsection{2 | Event-related potentials}

There was no significant effect for the P3 ERP component $(p=.89)$. There was a moderate increase in $\mathrm{P} 2$ amplitude 
T A B L E 2 Summary of statistical outcomes for behavioural and neurophysiological measures. Baseline and post-intervention summary measures are shown for mood, working memory and EEG outcomes. Paired-samples $t$ tests were used to examine changes from baseline to post. Equivalence tests were used to determine whether effects were significantly lower than the smallest effect size of interest, that is an effect size of Cohen's $d=0.3$

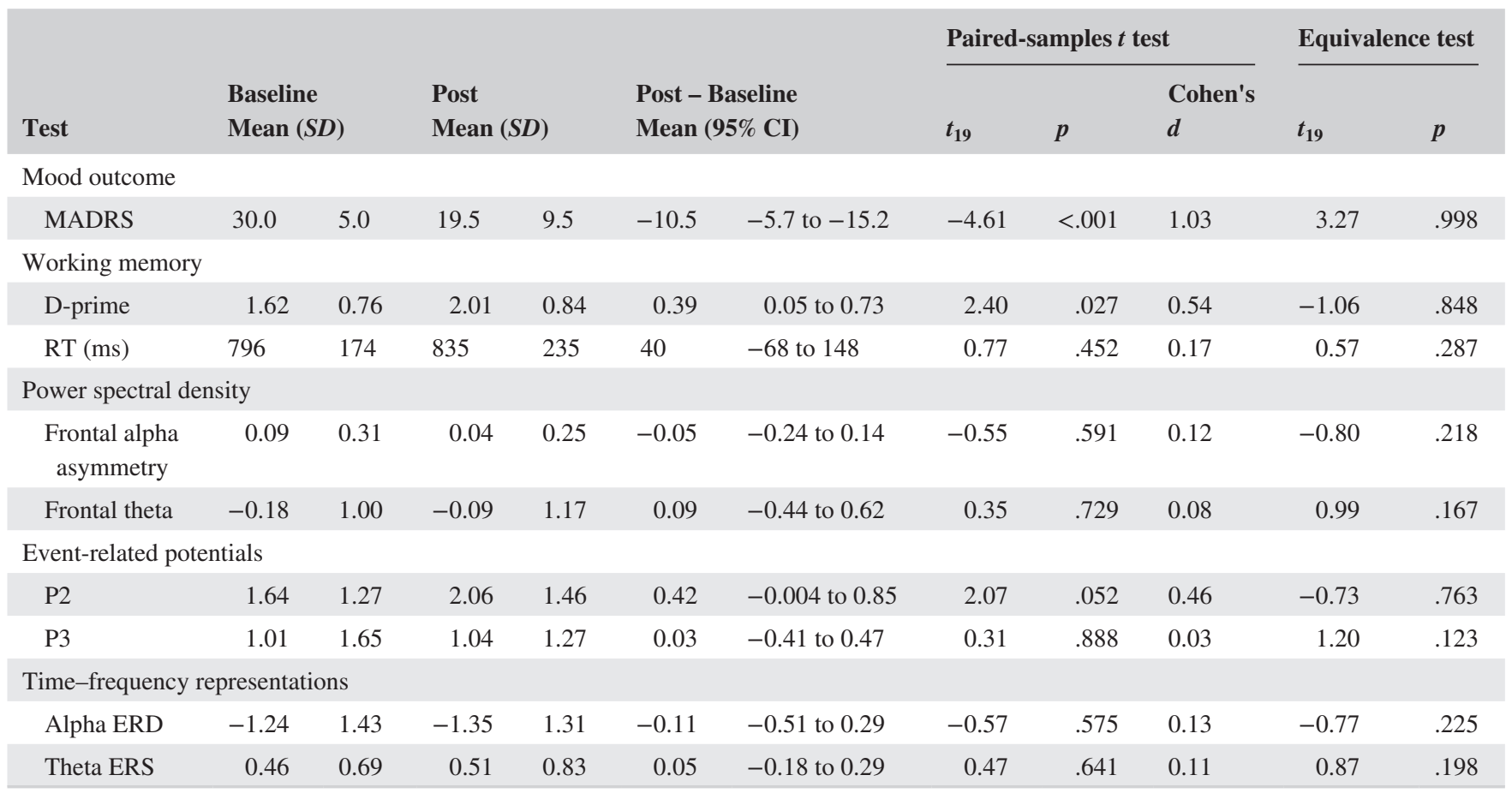

Note: MADRS, Montgomery-Asberg Depression Rating Scale (Montgomery \& Asberg, 1979); ERD, event-related desynchronisation; ERS, event-related synchronisation.

$(p=.05)$; however, this did not survive correction for multiple comparisons using the Bonferroni adjusted $p$-value threshold (i.e. $p<.008$ ). Equivalence testing for P2 and P3 components was not significant. No significant clusters were observed comparing ERP measures at BASELINE to POST (see Figure 4).

\subsection{3 | Time-frequency analysis}

There were no significant effects for alpha ERD $(p=.58)$ or theta ERS ( $p=.64$; Wilcoxon signed-rank test, $p=.93$ ). Likewise, equivalence testing was not significant for both measures. No significant clusters were observed at any frequency bands, channels or time points (see Figure 5).

\section{3 | Safety}

Safety was assessed using a side effects questionnaire adapted from Brunoni et al. (2011), which has been used in our prior studies (e.g. Loo et al., 2011). The combined tDCS and CET intervention was well-tolerated by participants and resulted in transient adverse events of mild-moderate severity. The most frequent side effects were skin redness, paraesthesia (tingling, burning and itching) and headache, in agreement with prior meta-analyses of tDCS adverse events (Moffa et al., 2017; Nikolin, Huggins, Martin, Alonzo, \& Loo, 2018a). As reported in our previous work examining the cognitive effects of tDCS with concurrent CET, treatment did not result in significant reductions in cognitive functioning (Martin et al., 2018). A summary of all adverse events is provided in Table 3.

\section{4 | DISCUSSION}

This study investigated the neurophysiological effects of tDCS combined with CET in participants with treatmentresistant depression. Following the intervention, participants improved in mood as well as working memory performance accuracy, but not response time, on a visual 3-back task. Contrary to our hypotheses, for EEG outcomes, there was no evidence of differences in resting-state measures (frontal alpha asymmetry and frontal theta) or in task-related measures (alpha ERD, theta ERS and the P3 ERP component). We found weak evidence to suggest that P2 amplitude, a marker of attentional processes, increased, but this result did not survive correction for multiple comparisons.

Combining tDCS with CET appears to be a promising augmentation strategy to improve therapeutic efficacy in treatment-resistant depression. In a clinical pilot study, we 
(a)

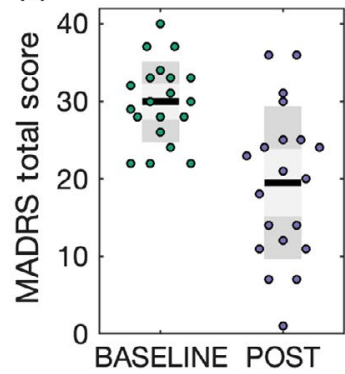

(b)

(c)

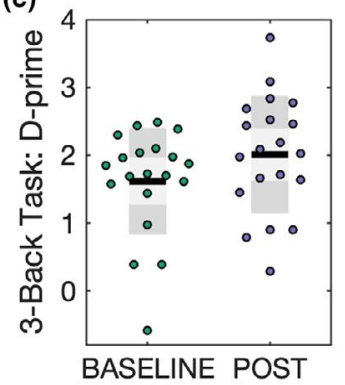

(e)

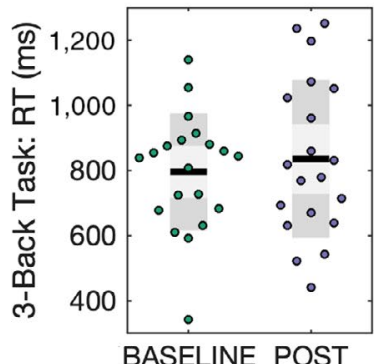

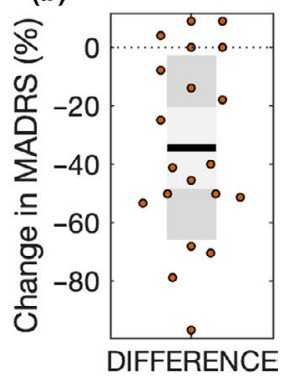

(d)

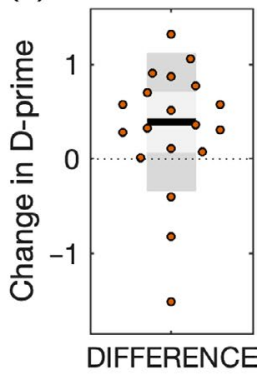

(f)

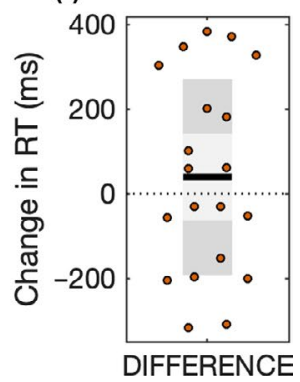

F I G URE 2 Behavioural outcomes. Scatter plots for mood and working memory performance scores are displayed at BASELINE and POST time points, in addition to change scores (DIFFERENCE). Black lines show the mean, light grey shaded boxes indicate the standard deviation, and dark grey regions indicate the $95 \%$ confidence interval. (a) Total MADRS scores; (b) MADRS difference scores, calculated as the percentage change in MADRS using the equation (POST - BASELINE)/BASELINE; (c) 3-back task d-prime scores; (d) D-prime difference scores, calculated as POST - BASELINE; (e) 3-back task response time (RT) scores; (f) RT difference scores, calculated as POST - BASELINE [Colour figure can be viewed at wileyonlinelibrary.com]

found that this combined intervention was feasible, safe and associated with significant antidepressant effect (Martin et al., 2018). Accompanying the improvement in mood, we observed a near-transfer effect from CET to improved discriminate sensitivity (i.e. d-prime) on the 3-back working memory task in the current report. In a similar study combining five repeated sessions of tDCS with cognitive control training, Segrave et al. (2014) also noted improved accuracy on an affective 2-back task. Our findings are in line with near-transfer effects following working memory training for improving cognition (Minear et al., 2016; Soveri, Karlsson, Waris, Grönholm-Nyman, \& Laine, 2017). A meta-analysis

by Schwaighofer, Fischer, and Bühner (2015) suggests that the near-transfer effect of working memory training has an effect size ranging between Hedge's $g=0.37-0.72$, which encompasses the effect size for d-prime observed in the present study (Cohen's $d=0.54$ ). In the absence of a control condition, however, it is difficult to determine whether working memory improvements observed in the current study are due to the intervention (i.e. near-transfer effects from CET) or may be associated with mood improvement.

Although there were no significant changes in neurophysiological measures after controlling for multiple comparisons, we found weak evidence that the intervention increased the P2 ERP amplitude. The P2 component has been linked to attentional processes (Kemp et al., 2006; Lijffijt et al., 2009; Luu et al., 2014; Vilà-Balló et al., 2018; Yuan et al., 2016)), whereas P3 is associated with higher-order cognitive functions such as target identification and categorisation (Friedman, Cycowicz, \& Gaeta, 2001; Kok, 2001; Rac-Lubashevsky \& Kessler, 2016). McEvoy et al. (1998) systematically investigated the impact of working memory load and practice effects, and similarly observed changes in $\mathrm{P} 2$, but not $\mathrm{P} 3$, amplitude. Our results therefore suggest that CET, which involves a working memory component, may improve lower-order processing and attentional capacity, observed as an increase in P2 amplitude, although the statistical evidence was only weak. In line with this interpretation, similar findings were obtained following 3 weeks of treatment for depression using transcranial magnetic stimulation, another form of non-invasive brain stimulation, which increased P2 ERP amplitudes during an oddball task (Choi et al., 2014). Likewise, Spronk, Arns, Bootsma, Ruth, and Fitzgerald (2008) observed a left lateralised increase in frontal P2 amplitude in depressed patients during an auditory oddball task following 20 treatment sessions of transcranial magnetic stimulation, providing additional support for improvements in sensory-attentional processes but not higher-order cognitive functions. Our results are also in agreement with Keeser et al. (2011), who investigated the acute after-effects of prefrontal tDCS on working memory functioning. They found an increase in P2 amplitude at midline frontal electrode $\mathrm{Fz}$, in conjunction with improved d-prime accuracy and reduced reaction times. However, it is important to note that these findings may reflect differing neuromodulatory processes compared to the long-term, cumulative effects investigated in the current study.

Resting-state EEG measures commonly associated with depression, such as frontal alpha asymmetry and frontal theta power, were not significantly altered by the treatment despite meaningful improvements in mood. These measures were hypothesised a priori to change with treatment because they had been linked to antidepressant response (Arns et al., 2016, 2015; 2016, 2015; Spronk et al., 2011). Recently, there have been some criticisms of the viability of alpha asymmetry as a relevant factor for depression (Van 
(a)

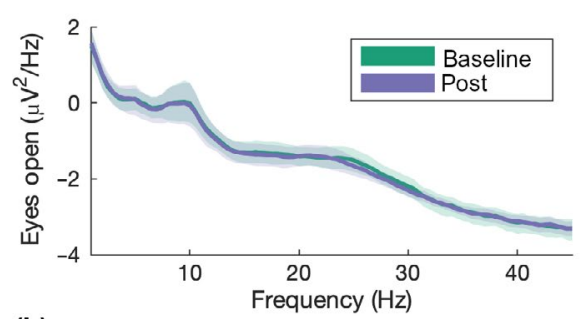

(b)

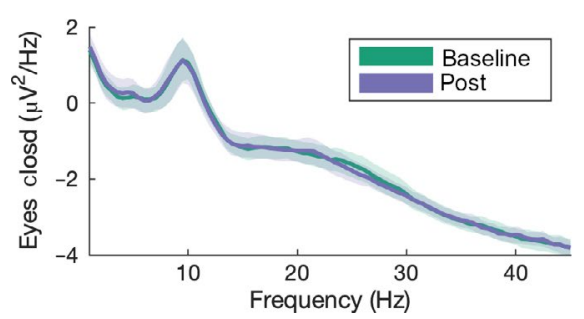

(c)

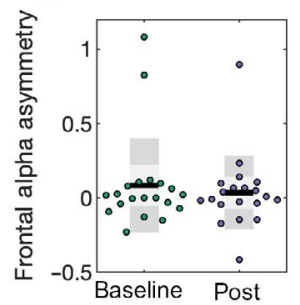

(d)

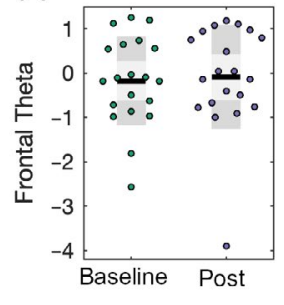

(e)

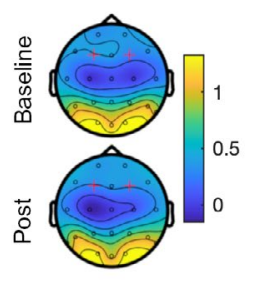

(f)

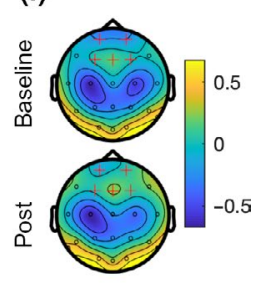

F I G U RE 3 Resting-state power spectral density. (a) Power spectra for eyes-open resting-state EEG with bootstrapped 95\% confidence intervals at channel Cz; (b) power spectra for eyes-closed resting-state EEG with bootstrapped 95\% confidence intervals at channel Cz; (c) frontal alpha asymmetry scatter plot during eyes-closed resting-state EEG, calculated as [F4 - F3]/[F4 + F3]. Black lines show the mean, light grey shaded boxes indicate the standard deviation, and dark grey regions indicate the $95 \%$ confidence interval; (d) frontal theta during eyes-closed resting state; (e) topography for alpha (8-13 Hz) power. Highlighted channels (F3 and F4) were used to calculate the frontal alpha asymmetry measure; (f) topography for theta (4-8 Hz) power. Highlighted channels were averaged to calculate the frontal theta index [Colour figure can be viewed at wileyonlinelibrary.com]

Der Vinne et al., 2017). Debener et al. (2000) challenge the notion that alpha asymmetry is a trait marker for depression, and report that increased variability, rather than increased alpha lateralisation, may be a more relevant measure. Similarly, frontal theta PSD may be better interpreted as a trait measure, reflecting structural or function abnormalities that contribute to the risk of developing depression, rather than a biomarker of the state of being depressed. Indeed, Hunter, Korb, Cook, and Leuchter (2013) found theta generated in the rostral anterior cingulate cortex to be a trait predictor of depression that does not change with treatment, that is it is invariant with regard to an individual's diagnosis of depression. Interestingly, supplementary analyses show a correlation between frontal alpha asymmetry $(p=.029)$ and mood scores (see Table S1). However, these must be interpreted with caution as correlations using small samples have a low probability of replication and can result in exaggerated effects through chance alone. Monte Carlo simulations show that correlations converge, that is, produce stable estimates close to the true effect, only as sample sizes approach $n=250$ (Schönbrodt \& Perugini, 2013).

Our lack of positive neurophysiological findings is generally consistent with the tDCS literature for protocols using repeated sessions of stimulation. To the best of our knowledge, only three studies have identified functional or structural changes associated with repeated sessions of anodal tDCS to the left DLPFC. Previous work by our group found an increase in neuroplasticity, quantified by probing motor cortex reactivity using transcranial magnetic stimulation, following prefrontal tDCS treatment for depression
(Player et al., 2014). In another clinical application, Ulam et al. (2015) examined the neurorehabilitatory effects of 10 consecutive sessions of left DLPFC tDCS for traumatic brain injury. They did not observe any significant effects from baseline to the final session of stimulation on EEG measures, including an analysis of frontal (F3) theta power, but did note a significant interaction effect compared to sham tDCS for delta and alpha frequency bands. Mondino et al. (2015) delivered 10 sessions of anodal stimulation over the left DLPFC, with cathodal stimulation over the temporo-parietal junction, for the treatment of auditory verbal hallucinations in schizophrenia and showed increased resting-state functional connectivity in the active tDCS group compared to sham. The present study did not include a sham control group, and thus, we were unable to examine interaction effects, which may have revealed similar neurophysiological changes.

There may be several reasons why we did not observe significant neurophysiological changes in the present study. Firstly, the modest sample size only allowed for detection of moderate-large effects. The estimated effect sizes for the EEG measures were small $(d=0.03-0.13)$, with the exception of $\mathrm{P} 2$ amplitude $(d=0.46)$. Although the majority of these effects were less than the smallest effect size of interest ( $d=0.3$ ), equivalence testing was non-significant for all neurophysiological outcomes. This suggests that there was sufficient variability in participant outcomes that the true effect could not be identified as less than our threshold criteria for equivalence testing. Thus, we are also unable to rule out the possibility of effect sizes greater than Cohen's 


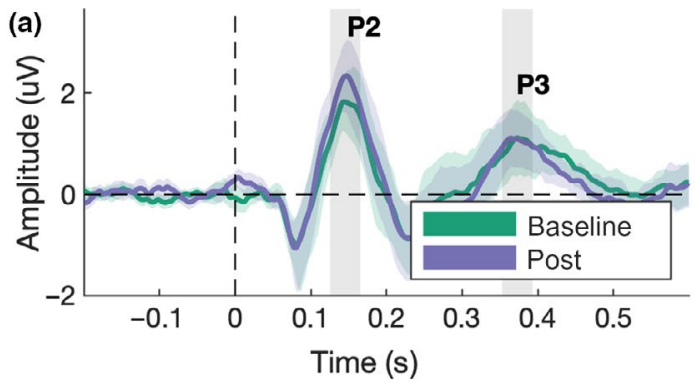

(b)
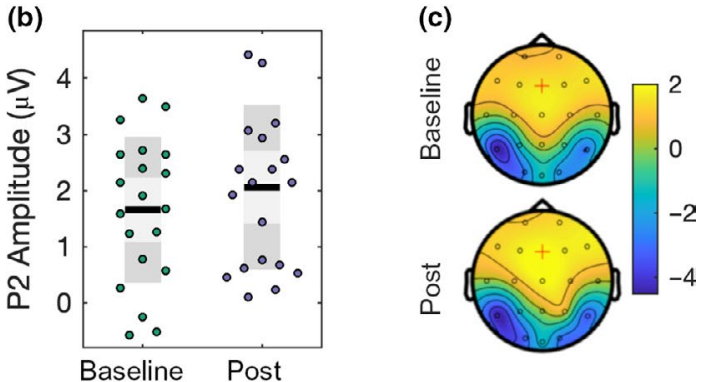

(d)

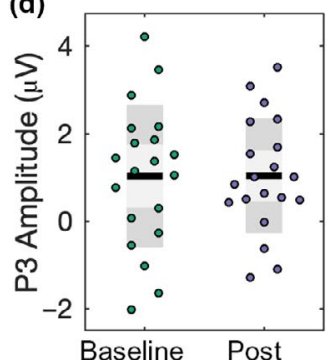

(e)

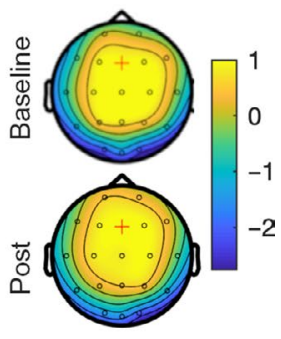

F I G U RE 4 Event-related potentials during the 3-back task. (a) ERPs with bootstrapped 95\% confidence intervals at channel Fz; (b) P2 component scatter plot. Black lines show the mean, light grey shaded boxes indicate the standard deviation, and dark grey regions indicate the $95 \%$ confidence interval; (c) topography for the P2 component (145.5 $\pm 20 \mathrm{~ms}$ ); (d) P3 component scatter plot; (e) topography for the P3 component $(373 \pm 20 \mathrm{~ms})$ [Colour figure can be viewed at wileyonlinelibrary.com]

$d=0.3$. Larger sample sizes are therefore required to overcome issues of heterogeneity and associated variability, inherent in depressed samples, and to thereby improve the ability to draw conclusions from statistical testing. For example, our results indicate that a sample of 39 participants is required to detect the effect size for P2 amplitude $(d=0.46)$ with $80 \%$ power.

Another potential reason for our null findings could be that the neurophysiological measures selected for hypothesis testing were suboptimal to detect treatment effects. To counteract this limitation, we examined resting-state PSD, as well as ERP and ERS/ERD during the 3-back task, using exploratory cluster-based non-parametric permutation tests to account for the possibility that an effect may lie beyond our a priori hypotheses, and found no significant clusters. Nevertheless, more sophisticated analyses, such as thetagamma phase-amplitude coupling (Noda et al., 2017; Sun et al., 2015), or dynamic causal modelling to determine changes (a)

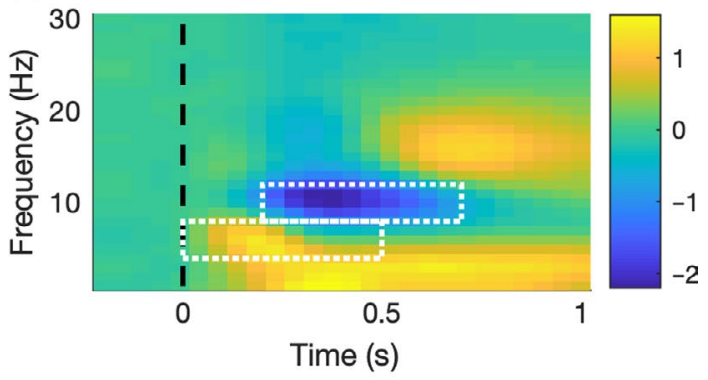

(b)

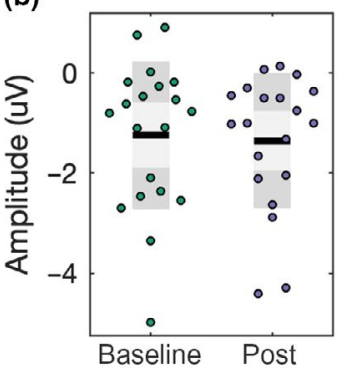

(c)

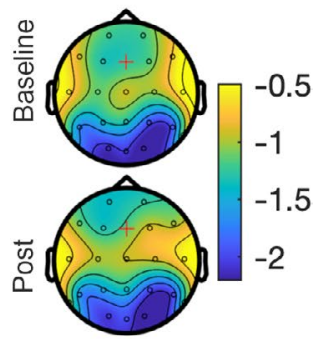

(d)

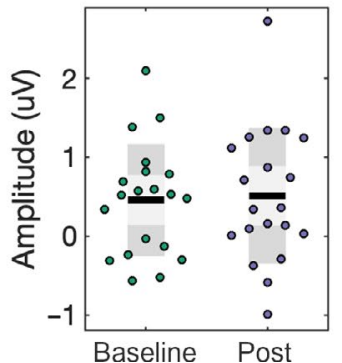

(e)

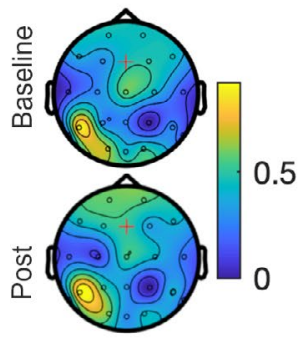

F I G URE 5 Time-frequency power during the 3-back task. (a) EEG power at channel Fz. White boxes indicate regions of interest for alpha ERD and theta ERS; (b) alpha ERD scatter plot. Black lines show the mean, light grey shaded boxes indicate the standard deviation, and dark grey regions indicate the $95 \%$ confidence interval; (c) topography for alpha ERD; (d) theta ERS scatter plot; (e) topography for theta ERS [Colour figure can be viewed at wileyonlinelibrary.com]

in effective connectivity between brain regions (Breakspear, 2017; Harding, Yücel, Harrison, Pantelis, \& Breakspear, 2015; Lu et al., 2012), may reveal the effects of the intervention. For example, theta connectivity localised to the anterior cingulate cortex has been identified as a predictor of antidepressant response to treatment courses using transcranial magnetic stimulation (Bailey et al., 2018; Narushima, McCormick, Yamada, Thatcher, \& Robinson, 2010) and sertraline (Pizzagalli et al., 2018).

Lastly, depression has been linked to abnormal activity in the subgenual anterior cingulate cortex, an area of the limbic system associated with emotional information processing (Pizzagalli et al., 2003; Drevets, Savitz, \& Trimble, 2008; Matthews, Strigo, Simmons, Yang, \& Paulus, 2008; Rentzsch et al., 2014). The Emotional Faces Memory Training task used for CET in the current study was designed to concurrently activate the cognitive control network and increase brain 
T A B L E 3 Adverse events. The group-level estimate of adverse event frequency is provided using the mean, standard deviation $(S D)$ and range of sessions in which an adverse event occurred. Incidence rates are also reported as a percentage (\%) of sessions in which an adverse event occurred out of the total of all tDCS and CET sessions conducted for the study

\begin{tabular}{lcll} 
& \multicolumn{2}{l}{ Frequency $(\#)$} & \\
\cline { 2 - 3 } Adverse event & Mean & $($ SD; range $)$ & Incidence $(\%)$ \\
Redness & 10.7 & $(6.2 ; 0-18)$ & 59.4 \\
Tingling & 6.7 & $(6.5 ; 0-18)$ & 37.2 \\
Burning & 4.3 & $(5.5 ; 0-18)$ & 23.9 \\
Itching & 2.8 & $(3.8 ; 0-16)$ & 15.6 \\
Headache & 1.9 & $(2.6 ; 0-7)$ & 10.3 \\
Fatigue & 1.5 & $(2.1 ; 0-8)$ & 8.1 \\
Others & 1.2 & $(2.2 ; 0-8)$ & 6.4 \\
Blurred vision & 0.9 & $(3.6 ; 0-16)$ & 4.7 \\
Light-headedness & 0.4 & $(0.7 ; 0-2)$ & 2.2 \\
Nausea & 0.4 & $(1.3 ; 0-6)$ & 1.9 \\
Pain & 0.3 & $(0.7 ; 0-2)$ & 1.7 \\
\hline
\end{tabular}

activity in these deeper limbic regions. Therefore, the effects of the intervention may be more readily observed within these subcortical structures. However, identification of changes at this depth may lie beyond the reach of the EEG setup used in this experiment. Though other EEG studies have successfully localised dysfunctional brain activity to sources within the anterior cingulate (Wacker, Dillon, \& Pizzagalli, 2009), this is typically achieved using EEG systems with a larger number of recording channels to better estimate source activity. It is also possible that greater effects would have been observed using task-related electrophysiological measures during an emotional processing task similar to the CET, such as passive viewing of emotionally salient images (MacNamara, Kotov, \& Hajcak, 2016). Stewart, Coan, Towers, and Allen (2014) found that alpha asymmetry was a better predictor when measured during an emotional task rather than during resting-state EEG. Unfortunately, these data were not collected, but may be a valuable addition to future studies seeking to examine similar interventions in depression.

\section{5 | CONCLUSION}

Combining tDCS with CET is a promising augmentation strategy for treatment-resistant depression. Although behavioural measures identified improvements in mood and working memory accuracy, the neurophysiological mechanisms underlying these improvements remain elusive. EEG analyses of resting-state (i.e. PSD) and task-related activity (i.e. ERPs and ERS/ERD) did not reveal substantial changes from baseline to post-treatment. There is, however, tentative evidence of an increase in P2 amplitude, suggesting that tDCS and CET may improve attention modulation and context updating in depressed participants. These findings do not rule out the possibility that more sophisticated EEG analyses, such as phase-amplitude coupling or functional/effective connectivity, may uncover significant effects and better explain observed antidepressant and working memory changes. Further research is needed using a sham control condition and a larger sample of participants to confirm our preliminary neurophysiological results and better quantify the mechanisms of action for this promising new intervention.

\section{ACKNOWLEDGEMENTS}

Donel Martin and Tjeerd Boonstra were both funded by a NARSAD Young Investigator Award (grant numbers 24015 and 26060, respectively) from the Brain and Behavior Research Foundation.

\section{CONFLICT OF INTEREST}

The authors declare they have no conflict of interest.

\section{DATA AVAILABILITY STATEMENT}

Data, MATLAB and R scripts used for EEG processing, calculation of neurophysiological measures and statistical analyses are available at the following link: https://github.com/ snikolin/tDCSandCET.

\section{AUTHOR CONTRIBUTIONS}

DM, TB and CL designed the study; SN performed the experiments; SN, DM and TB analysed the data; SN, DM, TB, $\mathrm{CL}$ and $\mathrm{BI}$ interpreted the results; $\mathrm{SN}$ prepared the figures; SN drafted the manuscript; SN, DM, CL, BI and TB edited/ revised the manuscript; and SN, DM, CL, BI and TB approved the final manuscript.

\section{ORCID}

Stevan Nikolin (D) https://orcid.org/0000-0003-4440-9273

Tjeerd W. Boonstra (iD https://orcid.

org/0000-0002-6969-7243

\section{REFERENCES}

APA (American Psychiatric Association) (1994) Diagnostic and Statistical Manual of Mental Disorders: DMS-IV. American Psychiatric Association.

Arns, M., Bruder, G., Hegerl, U., Spooner, C., Palmer, D. M., Etkin, A., ... Gordon, E. (2016). EEG alpha asymmetry as a gender-specific predictor of outcome to acute treatment with different antidepressant medications in the randomized iSPOT-D study. Clinical Neurophysiology, 127, 509-519. https://doi.org/10.1016/j.clinph.2015.05.032

Arns, M., Etkin, A., Hegerl, U., Williams, L. M., DeBattista, C., Palmer, D. M., ... Gordon, E. (2015). Frontal and rostral anterior cingulate (rACC) theta EEG in depression: Implications for treatment outcome? European Neuropsychopharmacology, 25, 1190-1200. https:// doi.org/10.1016/j.euroneuro.2015.03.007 
Bai, S., Dokos, S., Ho, K.-A., \& Loo, C. (2014). A computational modelling study of transcranial direct current stimulation montages used in depression. NeuroImage, 87, 332-344. https://doi.org/10.1016/j. neuroimage.2013.11.015

Bailey, N., Hoy, K., Rogasch, N., Thomson, R., McQueen, S., Elliot, D., ... Fitzgerald, P. (2018). Responders to rTMS for depression show increased fronto-midline theta and theta connectivity compared to non-responders. Brain Stimulation, 11, 190-203. https:// doi.org/10.1016/j.brs.2017.10.015

Bikson, M., name, A., \& Rahman, A. (2013). Origins of specificity during tDCS: Anatomical, activity-selective, and input-bias mechanisms. Frontiers in Human Neuroscience, 7, 688. https://doi. org/10.3389/fnhum.2013.00688

Blumberger, D., Tran, L., Fitzgerald, P., Hoy, K. B., \& Daskalakis, Z. J. (2012). A randomized double-blind sham-controlled study of transcranial direct current stimulation for treatment-resistant major depression. Frontiers in Psychiatry, 3, 74. https://doi.org/10.3389/ fpsyt.2012.00074

Bolognini, N., Vallar, G., Casati, C., Latif, L. A., El-Nazer, R., Williams, J., ... Fregni, F. (2011). Neurophysiological and behavioral effects of tDCS combined with constraint-induced movement therapy in poststroke patients. Neurorehabilitation and Neural Repair, 25, 819-829. https://doi.org/10.1177/1545968311411056

Breakspear, M. (2017). Dynamic models of large-scale brain activity. Nature Neuroscience, 20, 340. https://doi.org/10.1038/nn.4497

Brunoni, A. R., Amadera, J., Berbel, B., Volz, M. S., Rizzerio, B. G., \& Fregni, F. (2011). A systematic review on reporting and assessment of adverse effects associated with transcranial direct current stimulation. International Journal of Neuropsychopharmacology, 14, 1133-1145. https://doi.org/10.1017/S1461145710001690

Brunoni, A., Boggio, P., De Raedt, R., Benseñor, I., Lotufo, P., Namur, V., ... Vanderhasselt, M.-A. (2014). Cognitive control therapy and transcranial direct current stimulation for depression: A randomized, double-blinded, controlled trial. Journal of Affective Disorders, 162, 43-49. https://doi.org/10.1016/j.jad.2014.03.026

Brunoni, A. R., Moffa, A. H., Fregni, F., Palm, U., Padberg, F., Blumberger, D. M., ... Loo, C. K. (2016). Transcranial direct current stimulation for acute major depressive episodes: Meta-analysis of individual patient data. British Journal of Psychiatry, 208, 522 531. https://doi.org/10.1192/bjp.bp.115.164715

Brunoni, A. R., Moffa, A. H., Sampaio-Junior, B., Borrione, L., Moreno, M. L., Fernandes, R. A., ... Benseñor, I. M. (2017). Trial of electrical direct-current therapy versus escitalopram for depression. New England Journal of Medicine, 376, 2523-2533. https:// doi.org/10.1056/NEJMoa1612999

Brunoni, A. R., Valiengo, L., Baccaro, A., Zanao, T. A., de Oliveira, J. F., Goulart, A., ... Fregni, F. (2013). The sertraline vs electrical current therapy for treating depression clinical study: Results from a factorial, randomized, controlled trial. JAMA Psychiatry, 70, 383391. https://doi.org/10.1001/2013.jamapsychiatry.32

Brydges, C. R., \& Barceló, F. (2018). Functional dissociation of latency-variable, stimulus-and response-locked target P3 sub-components in task-switching. Frontiers in Human Neuroscience, 12, 60. https://doi.org/10.3389/fnhum.2018.00060

Choi, K. M., Jang, K.-M., Jang, K. I., Um, Y. H., Kim, M.-S., Kim, D.-W., ... Chae, J.-H. (2014). The effects of 3 weeks of rTMS treatment on P200 amplitude in patients with depression. Neuroscience Letters, 577, 22-27. https://doi.org/10.1016/j.neulet.2014.06.003

$\mathrm{R}$ Core Team (2018). R: A language and environment for statistical computing. Vienna, Austria: R Foundation for Statistical Computing.
Debener, S., Beauducel, A., Nessler, D., Brocke, B., Heilemann, H., \& Kayser, J. (2000). Is resting anterior EEG alpha asymmetry a trait marker for depression? Neuropsychobiology, 41, 31-37. https://doi. org/10.1159/000026630

Di Lazzaro, V., Dileone, M., Capone, F., Pellegrino, G., Ranieri, F., Musumeci, G., ... Fregni, F. (2014). Immediate and late modulation of interhemipheric imbalance with bilateral transcranial direct current stimulation in acute stroke. Brain Stimulation, 7, 841-848. https ://doi.org/10.1016/j.brs.2014.10.001

Diego, M. A., Field, T., \& Hernandez-Reif, M. (2001). CES-D depression scores are correlated with frontal EEG alpha asymmetry. Depression and Anxiety, 13, 32-37. https://doi. org/10.1002/1520-6394(2001)13:1<32:AID-DA5>3.0.CO;2-G

Dong, S., Reder, L. M., Yao, Y., Liu, Y., \& Chen, F. (2015). Individual differences in working memory capacity are reflected in different ERP and EEG patterns to task difficulty. Brain Research, 1616, 146-156. https://doi.org/10.1016/j.brainres.2015.05.003

Drevets, W. C., Savitz, J., \& Trimble, M. (2008). The subgenual anterior cingulate cortex in mood disorders. CNS Spectrums, 13, 663. https ://doi.org/10.1017/S1092852900013754

Fekadu, A., Wooderson, S., Donaldson, C., Markopoulou, K., Masterson, B., Poon, L., \& Cleare, A. J. (2009). A multidimensional tool to quantify treatment resistance in depression: The Maudsley staging method. The Journal of Clinical Psychiatry, 70, 177-184. https://doi.org/10.4088/JCP.08m04309

Friedman, D., Cycowicz, Y. M., \& Gaeta, H. (2001). The novelty P3: An event-related brain potential (ERP) sign of the brain's evaluation of novelty. Neuroscience \& Biobehavioral Reviews, 25, 355-373. https ://doi.org/10.1016/S0149-7634(01)00019-7

Gajewski, P. D., \& Falkenstein, M. (2018). ERP and behavioral effects of physical and cognitive training on working memory in aging: A randomized controlled study. Neural Plasticity, 2018, 1-12. https:// doi.org/10.1155/2018/3454835

Gevins, A., \& Smith, M. E. (2000). Neurophysiological measures of working memory and individual differences in cognitive ability and cognitive style. Cerebral Cortex, 10, 829-839. https://doi. org/10.1093/cercor/10.9.829

Gluck, M. E., Alonso-Alonso, M., Piaggi, P., Weise, C. M., Jumpertzvon Schwartzenberg, R., Reinhardt, M., ... Krakoff, J. (2015). Neuromodulation targeted to the prefrontal cortex induces changes in energy intake and weight loss in obesity. Obesity, 23, 2149-2156. https://doi.org/10.1002/oby.21313

Gomarus, H. K., Althaus, M., Wijers, A. A., \& Minderaa, R. B. (2006). The effects of memory load and stimulus relevance on the EEG during a visual selective memory search task: An ERP and ERD/ ERS study. Clinical Neurophysiology, 117, 871-884. https://doi. org/10.1016/j.clinph.2005.12.008

Gordon, E., Palmer, D. M., \& Cooper, N. (2010). EEG alpha asymmetry in schizophrenia, depression, PTSD, panic disorder, ADHD and conduct disorder. Clinical EEG and Neuroscience, 41, 178-183. https://doi.org/10.1177/155005941004100404

Haatveit, B. C., Sundet, K., Hugdahl, K., Ueland, T., Melle, I., \& Andreassen, O. A. (2010). The validity of d prime as a working memory index: Results from the "Bergen n-back task". Journal of Clinical and Experimental Neuropsychology, 32, 871-880.

Hamner, J., Villamar, M. F., Fregni, F., \& Taylor, J. A. (2015). Transcranial direct current stimulation (tDCS) and the cardiovascular responses to acute pain in humans. Clinical Neurophysiology, 126, 1039-1046. https://doi.org/10.1016/j. clinph.2014.08.019 
Han, L., Liu, Y., Zhang, D., Jin, Y., \& Luo, Y. (2013). Low-arousal speech noise improves performance in N-back task: An ERP study. PLoS ONE, 8, e76261-e76261. https://doi.org/10.1371/journ al.pone.0076261

Harding, I. H., Yücel, M., Harrison, B. J., Pantelis, C., \& Breakspear, M. (2015). Effective connectivity within the frontoparietal control network differentiates cognitive control and working memory. NeuroImage, 106, 144-153. https://doi.org/10.1016/j.neuro image.2014.11.039

Hunter, A. M., Korb, A. S., Cook, I. A., \& Leuchter, A. F. (2013). Rostral anterior cingulate activity in major depressive disorder: State or trait marker of responsiveness to medication? The Journal of Neuropsychiatry and Clinical Neurosciences, 25, 126-133. https ://doi.org/10.1176/appi.neuropsych.11110330

Iacoviello, B., \& Charney, D. (2015). Developing cognitive-emotional training exercises as interventions for mood and anxiety disorders. European Psychiatry, 30, 75-81. https://doi.org/10.1016/j. eurpsy.2014.09.415

Iacoviello, B. M., Wu, G., Alvarez, E., Huryk, K., Collins, K. A., Murrough, J. W., ... Charney, D. S. (2014). Cognitive-emotional training as an intervention for major depressive disorder. Depression and Anxiety, 31, 699-706. https://doi.org/10.1002/da.22266

Iosifescu, D. V. (2011). Electroencephalography-derived biomarkers of antidepressant response. Harvard Review of Psychiatry, 19, 144154. https://doi.org/10.3109/10673229.2011.586549

Keeser, D., Padberg, F., Reisinger, E., Pogarell, O., Kirsch, V., Palm, U., ... Mulert, C. (2011). Prefrontal direct current stimulation modulates resting EEG and event-related potentials in healthy subjects: A standardized low resolution tomography (sLORETA) study. NeuroImage, 55, 644-657. https://doi.org/10.1016/j.neuro image.2010.12.004

Kemp, A. H., Hopkinson, P. J., Stephan, B. C., Clark, C. R., Gordon, E., Bryant, R. A., \& Williams, L. M. (2006). Predicting severity of non-clinical depression: Preliminary findings using an integrated approach. Journal of Integrative Neuroscience, 5, 89-110. https:// doi.org/10.1142/S0219635206001069

Klimesch, W., Doppelmayr, M., \& Hanslmayr, S. (2006). Upper alpha ERD and absolute power: Their meaning for memory performance. Progress in Brain Research, 159, 151-165.

Klimesch, W., Schack, B., Schabus, M., Doppelmayr, M., Gruber, W., \& Sauseng, P. (2004). Phase-locked alpha and theta oscillations generate the $\mathrm{P} 1-\mathrm{N} 1$ complex and are related to memory performance. Cognitive Brain Research, 19, 302-316. https://doi.org/10.1016/j. cogbrainres.2003.11.016

Knott, V., Mahoney, C., Kennedy, S., \& Evans, K. (2000). Pre-treatment EEG and it's relationship to depression severity and paroxetine treatment outcome. Pharmacopsychiatry, 33, 201-205. https://doi. org/10.1055/s-2000-8356

Kok, A. (2001). On the utility of P3 amplitude as a measure of processing capacity. Psychophysiology, 38, 557-577. https://doi. org/10.1017/S0048577201990559

Koo, P. C., Thome, J., Berger, C., Foley, P., \& Hoeppner, J. (2017). Current source density analysis of resting state EEG in depression: A review. Journal of Neural Transmission, 124, 109-118. https:// doi.org/10.1007/s00702-015-1432-2

Krause, C. M., Sillanmäki, L., Koivisto, M., Saarela, C., Häggqvist, A., Laine, M., \& Hämäläinen, H. (2000). The effects of memory load on event-related EEG desynchronization and synchronization. Clinical Neurophysiology, 111, 2071-2078. https://doi.org/10.1016/ S1388-2457(00)00429-6
Kronberg, G., Bridi, M., Abel, T., Bikson, M., \& Parra, L. C. (2017). Direct current stimulation modulates LTP and LTD: Activity dependence and dendritic effects. Brain Stimulation, 10, 51-58. https:// doi.org/10.1016/j.brs.2016.10.001

Kronberg, G., Rahman, A., Lafon, B., Bikson, M., \& Parra, L. C. (2019). Direct current stimulation boosts associative hebbian synaptic plasticity and maintains its pathway specificity. BioRxiv, 562322.

Lakens, D. (2017). TOSTER: Two one-sided tests (TOST) equivalence testing. R package version 0.2. 5 .

Lijffijt, M., Lane, S. D., Meier, S. L., Boutros, N. N., Burroughs, S., Steinberg, J. L., ... Swann, A. C. (2009). P50, N100, and P200 sensory gating: Relationships with behavioral inhibition, attention, and working memory. Psychophysiology, 46, 1059-1068. https://doi. org/10.1111/j.1469-8986.2009.00845.x

Loo, C. K., Alonzo, A., Martin, D., Mitchell, P. B., Galvez, V., \& Sachdev, P. (2012). Transcranial direct current stimulation for depression: 3-week, randomised, sham-controlled trial. British Journal of Psychiatry, 200, 52-59. https://doi.org/10.1192/bjp. bp.111.097634

Loo, C. K., Husain, M. M., McDonald, W. M., Aaronson, S., O'Reardon, J. P., Alonzo, A., ... McClintock, S. M. (2018). International randomized-controlled trial of transcranial Direct Current Stimulation in depression. Brain Stimulation: Basic, Translational, and Clinical Research in Neuromodulation, 11, 125-133. https://doi. org/10.1016/j.brs.2017.10.011

Loo, C., Martin, D., Alonzo, A., Gandevia, S., Mitchell, P., \& Sachdev, P. (2011). Avoiding skin burns with transcranial direct current stimulation: Preliminary considerations. International Journal of Neuropsychopharmacology, 14, 425-426. https://doi.org/10.1017/ S1461145710001197

Lu, Q., Li, H., Luo, G., Wang, Y., Tang, H., Han, L., \& Yao, Z. (2012). Impaired prefrontal-amygdala effective connectivity is responsible for the dysfunction of emotion process in major depressive disorder: A dynamic causal modeling study on MEG. Neuroscience Letters, 523, 125-130. https://doi.org/10.1016/j.neulet.2012.06.058

Luu, P., Caggiano, D., Geyer, A., Lewis, J., Cohn, J., \& Tucker, D. (2014). Time-course of cortical networks involved in working memory. Frontiers in Human Neuroscience, 8. https://doi.org/10.3389/ fnhum.2014.00004

MacNamara, A., Kotov, R., \& Hajcak, G. (2016). Diagnostic and symptom-based predictors of emotional processing in generalized anxiety disorder and major depressive disorder: An event-related potential study. Cognitive Therapy and Research, 40, 275-289. https://doi. org/10.1007/s10608-015-9717-1

Maris, E., \& Oostenveld, R. (2007). Nonparametric statistical testing of EEG-and MEG-data. Journal of Neuroscience Methods, 164, 177190. https://doi.org/10.1016/j.jneumeth.2007.03.024

Martin, D. M., Alonzo, A., Mitchell, P. B., Sachdev, P., Gálvez, V., \& Loo, C. K. (2011). Fronto-extracephalic transcranial direct current stimulation as a treatment for major depression: An open-label pilot study. Journal of Affective Disorders, 134, 459-463. https://doi. org/10.1016/j.jad.2011.05.018

Martin, D., Teng, J., Lo, T., Alonzo, A., Goh, T., Iacoviello, B., ... Loo, C. (2018). Clinical pilot study of transcranial direct current stimulation combined with Cognitive Emotional Training for medication resistant depression. Journal of Affective Disorders, 232, 89-95. https://doi.org/10.1016/j.jad.2018.02.021

Matthews, S. C., Strigo, I. A., Simmons, A. N., Yang, T. T., \& Paulus, M. P. (2008). Decreased functional coupling of the amygdala and supragenual cingulate is related to increased depression in 
unmedicated individuals with current major depressive disorder. Journal of Affective Disorders, 111, 13-20. https://doi.org/10.1016/j. jad.2008.05.022

McEvoy, L. K., Smith, M. E., \& Gevins, A. (1998) Dynamic cortical networks of verbal and spatial working memory: effects of memory load and task practice. Cerebral Cortex, 8, 563-574.

Minear, M., Brasher, F., Guerrero, C. B., Brasher, M., Moore, A., \& Sukeena, J. (2016). A simultaneous examination of two forms of working memory training: Evidence for near transfer only. Memory \& Cognition, 44, 1014-1037. https://doi.org/10.3758/ s13421-016-0616-9

Missonnier, P., Deiber, M.-P., Gold, G., Millet, P., Pun, M.- G.-F., FazioCosta, L., ... Ibáñez, V. (2006). Frontal theta event-related synchronization: Comparison of directed attention and working memory load effects. Journal of Neural Transmission, 113, 1477-1486. https ://doi.org/10.1007/s00702-005-0443-9

Moffa, A. H., Brunoni, A. R., Fregni, F., Palm, U., Padberg, F., Blumberger, D. M., ... Loo, C. K. (2017). Safety and acceptability of transcranial direct current stimulation for the acute treatment of major depressive episodes: Analysis of individual patient data. Journal of Affective Disorders, 221, 1-5. https://doi.org/10.1016/j. jad.2017.06.021

Mondino, M., Jardri, R., Suaud-Chagny, M.-F., Saoud, M., Poulet, E., \& Brunelin, J. (2015). Effects of fronto-temporal transcranial direct current stimulation on auditory verbal hallucinations and resting-state functional connectivity of the left temporo-parietal junction in patients with schizophrenia. Schizophrenia Bulletin, 42, 318-326. https://doi.org/10.1093/schbul/sbv114

Montgomery, S., \& Asberg, M. (1979). MADRS scale. British Journal of Psychiatry, 134, 382-389.

Mrazek, D. A., Hornberger, J. C., Altar, C. A., \& Degtiar, I. (2014). A review of the clinical, economic, and societal burden of treatment-resistant depression: 1996-2013. Psychiatric Services, 65, 977-987. https://doi.org/10.1176/appi.ps.201300059

Mull, B. R., \& Seyal, M. (2001). Transcranial magnetic stimulation of left prefrontal cortex impairs working memory. Clinical Neurophysiology, 112, 1672-1675. https://doi.org/10.1016/ S1388-2457(01)00606-X

Mutz, J., Vipulananthan, V., Carter, B., Hurlemann, R., Fu, C. H., \& Young, A. H. (2019). Comparative efficacy and acceptability of non-surgical brain stimulation for the acute treatment of major depressive episodes in adults: systematic review and network meta-analysis. BMJ, 364, 1079. https://doi.org/10.1136/bmj.11079

Narushima, K., McCormick, L. M., Yamada, T., Thatcher, R. W., \& Robinson, R. G. (2010). Subgenual cingulate theta activity predicts treatment response of repetitive transcranial magnetic stimulation in participants with vascular depression. The Journal of Neuropsychiatry and Clinical Neurosciences, 22, 75-84. https://doi. org/10.1176/jnp.2010.22.1.75

Nikolin, S., Huggins, C., Martin, D., Alonzo, A., \& Loo, C. K. (2018a). Safety of repeated sessions of transcranial direct current stimulation: A systematic review. Brain Stimulation: Basic, Translational, and Clinical Research in Neuromodulation, 11, 278-288. https://doi. org/10.1016/j.brs.2017.10.020

Nikolin, S., Martin, D., Loo, C. K., \& Boonstra, T. W. (2018b). Effects of TDCS dosage on working memory in healthy participants. Brain Stimulation.

Noda, Y., Zomorrodi, R., Saeki, T., Rajji, T. K., Blumberger, D. M., Daskalakis, Z. J., \& Nakamura, M. (2017). Resting-state EEG gamma power and theta-gamma coupling enhancement following high-frequency left dorsolateral prefrontal rTMS in patients with depression. Clinical Neurophysiology, 128, 424-432. https://doi. org/10.1016/j.clinph.2016.12.023

Oostenveld, R., Fries, P., Maris, E., \& Schoffelen, J.-M. (2011). FieldTrip: Open source software for advanced analysis of MEG, EEG, and invasive electrophysiological data. Computational Intelligence and Neuroscience, 2011, 1. https://doi.org/10.1155/2011/156869

Palm, U., Schiller, C., Fintescu, Z., Obermeier, M., Keeser, D., Reisinger, E., ... Padberg, F. (2012). Transcranial direct current stimulation in treatment resistant depression: A randomized double-blind, placebo-controlled study. Brain Stimulation, 5, 242-251. https://doi. org/10.1016/j.brs.2011.08.005

Pizzagalli, D., Hendrick, A. M., Horras, K. A., \& Davidson, R. J. (2002). Anterior cingulate theta activity is associated with degree of treatment response in major depression. In K. Hirata (Ed.), International Congress Series ( Vol. 1232, pp. 711-717). Tochigi, Japan: Elsevier. https://doi.org/10.1016/S0531-5131(01)00810-X

Pizzagalli, D. A., Oakes, T. R., \& Davidson, R. J. (2003). Coupling of theta activity and glucose metabolism in the human rostral anterior cingulate cortex: An EEG/PET study of normal and depressed subjects. Psychophysiology, 40, 939-949. https://doi. org/10.1111/1469-8986.00112

Pizzagalli, D. A., Webb, C. A., Dillon, D. G., Tenke, C. E., Kayser, J., Goer, F., ... Trivedi, M. H. (2018). Pretreatment rostral anterior cingulate cortex theta activity in relation to symptom improvement in depression: A randomized clinical trial. JAMA Psychiatry, 75, 547-554. https://doi.org/10.1001/jamapsychiatry.2018.0252

Player, M. J., Taylor, J. L., Weickert, C. S., Alonzo, A., Sachdev, P. S., Martin, D., ... Loo, C. K. (2014). Increase in PAS-induced neuroplasticity after a treatment course of transcranial direct current stimulation for depression. Journal of Affective Disorders, 167, 140-147. https://doi.org/10.1016/j.jad.2014.05.063

Polich, J. (2007). Updating P300: An integrative theory of P3a and P3b. Clinical Neurophysiology, 118, 2128-2148. https://doi. org/10.1016/j.clinph.2007.04.019

Powell, T. Y., Boonstra, T. W., Martin, D. M., Loo, C. K., \& Breakspear, M. (2014). Modulation of cortical activity by transcranial direct current stimulation in patients with affective disorder. PLOS ONE, 9, e98503. https://doi.org/10.1371/journal.pone.0098503

Rac-Lubashevsky, R., \& Kessler, Y. (2016). Dissociating working memory updating and automatic updating: The reference-back paradigm. Journal of Experimental Psychology: Learning, Memory, and Cognition, 42, 951.

Rentzsch, J., Adli, M., Wiethoff, K., de Castro, A.- G.-C., \& Gallinat, J. (2014). Pretreatment anterior cingulate activity predicts antidepressant treatment response in major depressive episodes. European Archives of Psychiatry and Clinical Neuroscience, 264, 213-223. https://doi.org/10.1007/s00406-013-0424-1

Schönbrodt, F. D., \& Perugini, M. (2013). At what sample size do correlations stabilize? Journal of Research in Personality, 47, 609-612. https://doi.org/10.1016/j.jrp.2013.05.009

Schwaighofer, M., Fischer, F., \& Bühner, M. (2015). Does working memory training transfer? A meta-analysis including training conditions as moderators. Educational Psychologist, 50, 138-166. https:// doi.org/10.1080/00461520.2015.1036274

Segrave, R., Arnold, S., Hoy, K., \& Fitzgerald, P. (2014). Concurrent cognitive control training augments the antidepressant efficacy of tDCS: A pilot study. Brain Stimulation: Basic, Translational, and Clinical Research in Neuromodulation, 7, 325-331. https://doi. org/10.1016/j.brs.2013.12.008 
Soveri, A., Karlsson, E. P., Waris, O., Grönholm-Nyman, P., \& Laine, M. (2017). Pattern of near transfer effects following working memory training with a dual n-back task. Experimental Psychology.

Spronk, D., Arns, M., Barnett, K., Cooper, N., \& Gordon, E. (2011). An investigation of EEG, genetic and cognitive markers of treatment response to antidepressant medication in patients with major depressive disorder: A pilot study. Journal of Affective Disorders, 128, 41-48. https://doi.org/10.1016/j.jad.2010.06.021

Spronk, D., Arns, M., Bootsma, A., van Ruth, R., \& Fitzgerald, P. B. (2008). Long term effects of left frontal rTMS on EEG and ERPs in patients with depression. Clinical EEG and Neuroscience, 39, 118-124. https://doi.org/10.1177/155005940803900305

Stewart, J. L., Bismark, A. W., Towers, D. N., Coan, J. A., \& Allen, J. J. (2010). Resting frontal EEG asymmetry as an endophenotype for depression risk: Sex-specific patterns of frontal brain asymmetry. Journal of Abnormal Psychology, 119, 502. https://doi.org/10.1037/a0019196

Stewart, J. L., Coan, J. A., Towers, D. N., \& Allen, J. J. (2014). Resting and task-elicited prefrontal EEG alpha asymmetry in depression: Support for the capability model. Psychophysiology, 51, 446-455. https://doi.org/10.1111/psyp.12191

Stipacek, A., Grabner, R., Neuper, C., Fink, A., \& Neubauer, A. (2003). Sensitivity of human EEG alpha band desynchronization to different working memory components and increasing levels of memory load. Neuroscience Letters, 353, 193-196. https://doi.org/10.1016/j. neulet.2003.09.044

Sun, Y., Giacobbe, P., Tang, C. W., Barr, M. S., Rajji, T., Kennedy, S. H., ... Daskalakis, Z. J. (2015). Deep brain stimulation modulates gamma oscillations and theta-gamma coupling in treatment resistant depression. Brain Stimulation, 8, 1033-1042. https://doi. org/10.1016/j.brs.2015.06.010

Ulam, F., Shelton, C., Richards, L., Davis, L., Hunter, B., Fregni, F., \& Higgins, K. (2015). Cumulative effects of transcranial direct current stimulation on EEG oscillations and attention/working memory during subacute neurorehabilitation of traumatic brain injury. Clinical Neurophysiology, 126, 486-496. https://doi.org/10.1016/j. clinph.2014.05.015

Van Der Vinne, N., Vollebregt, M. A., Van Putten, M. J., \& Arns, M. (2017). Frontal alpha asymmetry as a diagnostic marker in depression: Fact or fiction? A meta-analysis. Neuroimage: Clinical, 16, 79-87. https://doi.org/10.1016/j.nicl.2017.07.006

Vilà-Balló, A., Salmi, J., Soveri, A., Rodríguez-Fornells, A., Lehtonen, M., \& Laine, M. (2018). Neural signatures for active maintenance and interference during working memory updating. Biological Psychology, 132, 233-243. https://doi.org/10.1016/j.biopsycho.2018.01.007
Wacker, J., Dillon, D. G., \& Pizzagalli, D. A. (2009). The role of the nucleus accumbens and rostral anterior cingulate cortex in anhedonia: Integration of resting EEG, fMRI, and volumetric techniques. NeuroImage, 46, 327-337. https://doi.org/10.1016/j.neuro image.2009.01.058

Welch, P. (1967). The use of fast Fourier transform for the estimation of power spectra: A method based on time averaging over short, modified periodograms. IEEE Transactions on Audio and Electroacoustics, 15, 70-73. https://doi.org/10.1109/ TAU.1967.1161901

Wianda, E., \& Ross, B. (2019). The roles of alpha oscillation in working memory retention. Brain and Behavior, 9(4), e01263. https://doi. org/10.1002/brb3.1263

Yuan, Y., Leung, A. W. S., Duan, H., Zhang, L., Zhang, K., Wu, J., \& Qin, S. (2016). The effects of long-term stress on neural dynamics of working memory processing: An investigation using ERP. Scientific Reports, 6, 23217-23217. https://doi.org/10.1038/ srep 23217

Zaehle, T., Sandmann, P., Thorne, J. D., Jäncke, L., \& Herrmann, C. S. (2011). Transcranial direct current stimulation of the prefrontal cortex modulates working memory performance: Combined behavioural and electrophysiological evidence. BMC Neuroscience, 12, 2. https://doi.org/10.1186/1471-2202-12-2

Zhao, X., Li, X., \& Yao, L. (2017). Localized fluctuant oscillatory activity by working memory load: A simultaneous EEG-fMRI study. Frontiers in Behavioral Neuroscience, 11, 215. https://doi. org/10.3389/fnbeh.2017.00215

\section{SUPPORTING INFORMATION}

Additional supporting information may be found online in the Supporting Information section.

How to cite this article: Nikolin S, Martin D, Loo CK, Iacoviello BM, Boonstra TW. Assessing neurophysiological changes associated with combined transcranial direct current stimulation and cognitiveemotional training for treatment-resistant depression. Eur J Neurosci. 2020;51:2119-2133. https://doi. org/10.1111/ejn.14656 